\title{
Phase Transformation During Intercritical Tempering with High Heating Rate in a Fe-13\%Cr-4\%Ni-Mo Stainless Steel
}

\author{
Pei WANG ${ }^{\dagger}$, Shenghua ZHANG, Shanping LU, Dianzhong LI and Yiyi LI \\ Shenyang National Laboratory for Materials Science, Institute of Metal Research, Chinese Academy of Sciences, Shenyang
} 110016, China

[Manuscript received 26 May 2013, in revised form 4 July 2013]

(c) The Chinese Society for Metals and Springer-Verlag Berlin Heidelberg

\begin{abstract}
The phase transformation from martensite to austenite during intercritical tempering with high heating rate in a low carbon martensitic stainless steel Fe-13\% Cr-4\%Ni-Mo has been investigated to clarify the microstructure evolution in some regions of the weld joint heat affected zone (HAZ). The experimental results indicate that the start and finish temperatures of the martensite to austenite transformation keep constant when the heating rate is higher than $10 \mathrm{~K} / \mathrm{s}$, and the transformation is much faster than nickel diffusion. The mechanism of the martensite to austenite transformation changes from diffusion to diffusionless during the intercritical tempering when the heating rate is higher than $10 \mathrm{~K} / \mathrm{s}$. The diffusionless transformation and higher $A_{\mathrm{s}}$ temperature render it difficult for any austenite to remain at room temperature during the intercritical tempering with high heating rate that occurs in the HAZ. Adding a proper intercritical tempering with low heating rate can induce some reversed austenite in the rapid heated sample.
\end{abstract}

\section{KEY WORDS: Martensitic stainless steel; Phase transformation; Intercritical tempering;} Heating rate; Microstructure

\section{Introduction}

Low carbon martensitic stainless steel Fe- $13 \% \mathrm{Cr}-$ $4 \% \mathrm{Ni}-\mathrm{Mo}$ is widely used in hydraulic turbine runners, valve bodies and high pressure pipes in power generation. The phase transformation from martensite to austenite during the intercritical tempering is an important phenomenon, which determines the amount and distribution of the reversed austenite and significantly influences the strength-ductility balance of the material $^{[1-5]}$. Extensive researches have been conducted on the phase transformation with low heating rate $^{[1-6]}$ in order to design heat treatment process for the castings. With the low heating rate, the volume fraction of austenite increases gradually with increasing isothermal holding time and the growth

\footnotetext{
† Corresponding author. Assist. Prof., Ph.D.; Tel.: +86 24 83970106; Fax: +86 24 83970097; E-mail address: pwang@imr.ac.cn (Pei WANG)
}

DOI: $10.1007 / \mathrm{s} 40195-013-0314-6$ of austenite is accompanied by the enrichment of $\mathrm{Ni}$, indicating that the phase transformation is controlled by diffusion ${ }^{[5-8]}$. However, the martensite to austenite phase transformation with high heating rate, which is also important as it usually occurs in welding process, has not been fully investigated.

The welding process is required for this material to be used in hydraulic turbine runner and other machines. Generally, the Fe-13\%Cr-4\%Ni-Mo steel has good weldability. However, without post weld heat treatment, the toughness and plasticity of the weld joint are always lower than the base metal. It has been found that regions in the heat affected zone (HAZ) of the weld joint that experience intercritical tempering with rapid heating rate in the single- or multi-pass welding, have no reversed austenite ${ }^{[9]}$, which could contribute to the poor toughness of the weld joint.

Previous researches show that the reversed austenite in $\mathrm{Fe}-13 \% \mathrm{Cr}-4 \% \mathrm{Ni}-\mathrm{Mo}$ stainless steel remains to room temperature due to segregation of austenite stabilizing elements in the diffusional phase transforma- 
Table 1 Chemical composition of the experimental alloy (wt. \%)

\begin{tabular}{ccccccccc}
\hline $\mathrm{C}$ & $\mathrm{Si}$ & $\mathrm{Mn}$ & $\mathrm{S}$ & $\mathrm{P}$ & $\mathrm{Cr}$ & $\mathrm{Ni}$ & $\mathrm{Mo}$ & $\mathrm{Fe}$ \\
\hline 0.037 & 0.28 & 0.75 & 0.008 & 0.019 & 12.7 & 4.1 & 0.53 & Balance \\
\hline
\end{tabular}

Table 2 Tempering conditions used for different samples

\begin{tabular}{|c|c|c|c|c|}
\hline Sample & & Heating rate $(\mathrm{K} / \mathrm{s})$ & Temperature (K) & Holding time (s) \\
\hline No.1 & & 0.05 & 893 & 900 \\
\hline No.2 & & 0.05 & 893 & 25200 \\
\hline No.3 & & 0.05 & 993 & 900 \\
\hline No.4 & & 0.05 & 993 & 25200 \\
\hline No.5 & & 50 & 993 & 0 \\
\hline No.6 & & 50 & 993 & 900 \\
\hline No.7 & & 50 & 993 & 1800 \\
\hline No.8 & & 50 & 953 & 900 \\
\hline No.9 & & 50 & 973 & 900 \\
\hline No.10 & & 50 & 1023 & 900 \\
\hline \multirow[t]{2}{*}{ No.11 } & First stage & 50 & 993 & 900 \\
\hline & Second stage & 0.05 & 893 & 900 \\
\hline
\end{tabular}

tion. Therefore, if the transformation is diffusionless, the reversed austenite cannot remain at room temperature because the elements do not have time to segregate in the austenite. The transition from diffusion to diffusionless phase transformation has been observed in other stainless steels when the heating rate is high ${ }^{[10-12]}$. In this paper, we will analyze the phase transformation mode to explain the absence of reversed austenite in the $\mathrm{HAZ}$ of $\mathrm{Fe}-13 \% \mathrm{Cr}-4 \% \mathrm{Ni}-$ Mo stainless steel and propose a solution to introduce some austenite in it. It is theoretically important to investigate the martensite to austenite phase transformation with high heating rate for the fundamental understanding of the phase transformation mechanism of the investigated steel and also technologically important for understanding the microstructures of the HAZ and designing a proper post-weld heat treatment.

\section{Experimental}

The temperature gradient in the HAZ leads to a corresponding change of microstructure, which may introduce unnecessary complexity into the investigation of the martensite to austenite phase transformation. Thus, the martensite to austenite transformation in a normalized material during intercritical tempering with high heating rate was chosen to reveal the microstructure evolution in some regions in HAZ of a multi-pass weld joint.

The present alloy was melted in an electric arc furnace and a vacuum oxygen decarburization (VOD) furnace consecutively, and then poured into a sand mold (200 mm $\times 100 \mathrm{~mm} \times 80 \mathrm{~mm})$. Then, smaller blocks were machined from the material by wire electrical discharge machining for subsequent experiments. The chemical composition of the investigated steel is given in Table 1.

Prior to intercritical tempering, the material was annealed at $1423 \mathrm{~K}$ for $20 \mathrm{~h}$ to eliminate the microsegregation and then air-quenched after austenization at $1323 \mathrm{~K}$ for $2 \mathrm{~h}$ to obtain single-phase lath martensite. After then, the material was machined to cylindrical specimens $(\phi 3 \mathrm{~mm} \times 10 \mathrm{~mm})$. Firstly, a series of samples were continuously heated up to $1323 \mathrm{~K}$ with various heating rates ranging from $0.05 \mathrm{~K} / \mathrm{s}$ to $200 \mathrm{~K} / \mathrm{s}$ in an induction heating dilatometric machine (Linseis RITA L78) to determine the phase transformation temperatures at different heating rates. Secondly, another series of samples were tempered at different temperatures with various holding time and heating rates according to the measured phase transformation temperatures in a thermal dilatometer. The heat treatment conditions of the samples are listed in Table 2.

After tempering, the XRD samples were cut from the dilatometric samples and ground using waterabrasive paper. And then the samples were electropolished in a solution of perchloric acid $(100 \mathrm{~mL})$ and ethanol $(200 \mathrm{~mL})$ at room temperature to remove the stress-affected layer during the grinding. The XRD data were collected using $\mathrm{Cu} K \alpha$ radiation in the range of $40^{\circ} \leq 2 \theta \leq 100^{\circ}$ with a step of $0.02^{\circ}$. The thin foils for TEM observation were cut from the dilatometric sample and polished using the twin-jet electropolishing method with a solution of $6 \%$ nital at $250 \mathrm{~K}$. The TEM observations were carried out using a Tecnai F20 transmission electron microscope operated at $200 \mathrm{kV}$. The microhardness of the sample was measured by a Leco LM247AT micro hardness tester with a load of $5 \mathrm{~N}$ and a loading time of $15 \mathrm{~s}$.

\section{Results and Discussion}

\subsection{Dilatometric results and analysis}

Fig. 1 shows the relationship between the start and finish temperatures of the reverse transformation ( $A_{\mathrm{s}}$ and $A_{\mathrm{f}}$, respectively) of the experimental steel 


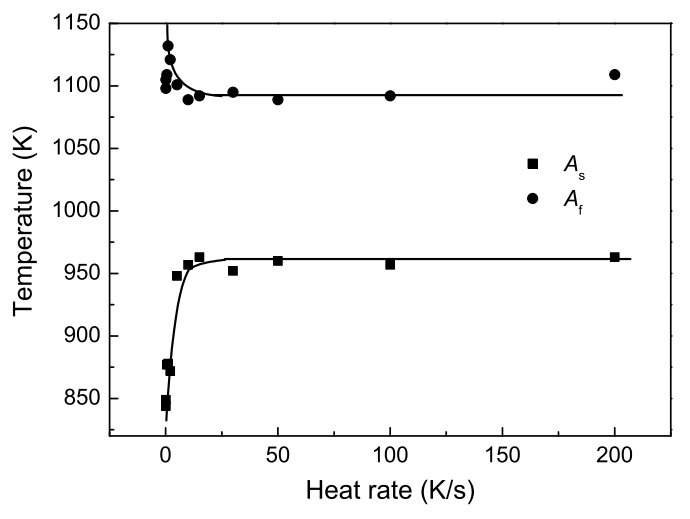

Fig. 1 The relationship between the $A_{\mathrm{s}}$ and $A_{\mathrm{f}}$ of the investigated steel and the heating rate

and the heating rate. When the heating rate is increased to $10 \mathrm{~K} / \mathrm{s}$, the $A_{\mathrm{s}}$ increases and $A_{\mathrm{f}}$ decreases. When the heating rate is higher than $10 \mathrm{~K} / \mathrm{s}, A_{\mathrm{s}}$ and $A_{\mathrm{f}}$ are independent of the heating rate. The different behavior of the $A_{\mathrm{s}}$ and $A_{\mathrm{f}}$ leads to a decrease in the phase transformation temperature range (i.e. from $A_{\mathrm{f}}$ to $A_{\mathrm{s}}$ ) from $254 \mathrm{~K}$ (heating rate is $0.05 \mathrm{~K} / \mathrm{s}$ ) to $130 \mathrm{~K}$ (heating rate is $10 \mathrm{~K} / \mathrm{s}$ ). After that, the phase transformation temperature range keeps constant. The $A_{\mathrm{s}}$ increases with increasing heating rate up to $10 \mathrm{~K} / \mathrm{s}$ because the higher heating rate delays the start point of the diffusional phase transformation ${ }^{[11,12]}$. When the heating rate is higher than $10 \mathrm{~K} / \mathrm{s}$, the $A_{\mathrm{s}}$ and $A_{\mathrm{f}}$ are not influenced by the heating rate, suggesting a diffusionless phase transformation ${ }^{[11-14]}$. Additionally, Song et al. ${ }^{[4]}$ has found that the austenite had the same chemical compositions as the martensite matrix when the austenizing temperature higher than $953 \mathrm{~K}$, which also confirms the diffusionless transformation.

The curves show the relationship of length increase $v s$. temperature of the samples heated up to $1323 \mathrm{~K}$ with different heating rates are plotted in Fig. 2. When the heating rate is $0.05 \mathrm{~K} / \mathrm{s}$, the martensite to austenite transformation shows two steps in a wide temperature range in the heating process. It can be clearly identified using the first-order derivative of the dilatometric curve in the transformation range, which has two extreme points (as shown in Fig. 2(a) $)^{[5,15]}$. This is due to the fact that the martensite to austenite phase transformation is controlled by diffusion and the austenite stabilizing elements diffuse from the subsequently transformed martensite to the new austenite during the phase transformation, when the heating rate is low. The continuous dilution of the austenite stabilizing elements in the later transformed martensite raises the $A_{\mathrm{s}}$ and $A_{\mathrm{f}}$. Therefore, if along with the elements redistribution, the diffusional phase transformation splits to two steps and the phase transformation temperature range is extended. Therefore, the $A_{\mathrm{s}}$ and $A_{\mathrm{f}}$ in the first step phase transformation are named as $A_{\mathrm{s} 1}$ and $A_{\mathrm{f} 1}$, while the $A_{\mathrm{s}}$ and $A_{\mathrm{f}}$ in the second step phase transformation are termed as $A_{\mathrm{s} 2}$
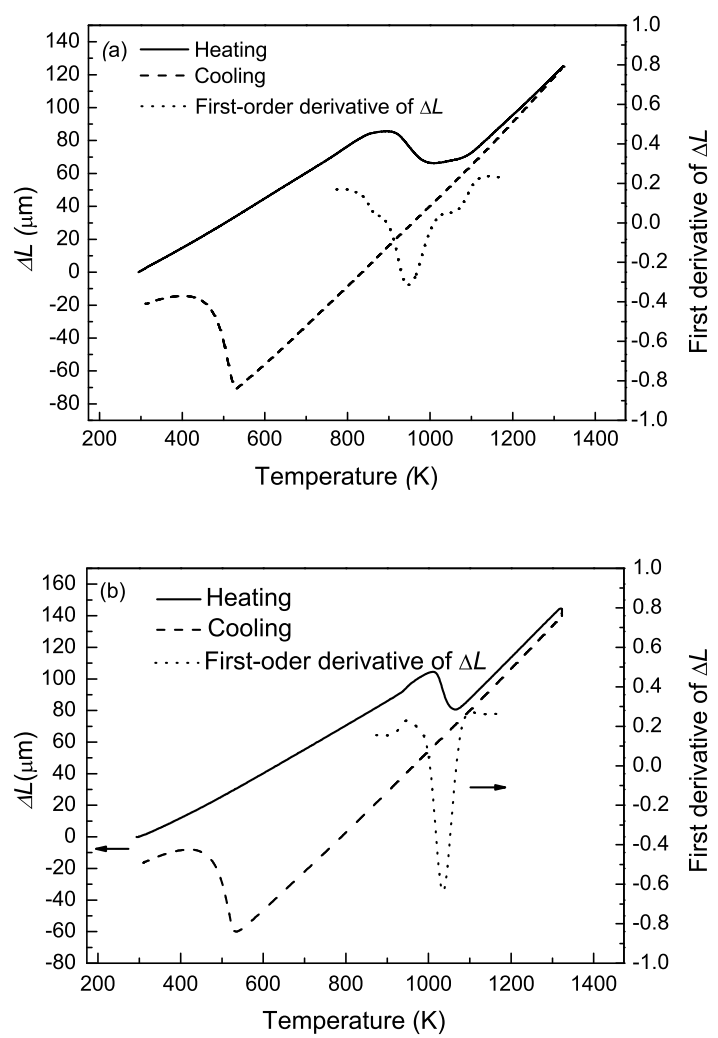

Fig. 2 The dilatometric curves of the sample with heating rate of (a) $0.05 \mathrm{~K} / \mathrm{s}$ and (b) $50 \mathrm{~K} / \mathrm{s}$

and $A_{\mathrm{f} 2}$. The $A_{\mathrm{s}}$ and $A_{\mathrm{f}}$ of the material are determined by $A_{\mathrm{s} 1}$ and $A_{\mathrm{f} 2}$, respectively. Generally, the $A_{\mathrm{s} 1}$ and $A_{\mathrm{f} 1}$ increase with the increasing heating rate. However, along with the heating rate increasing, the separation of the phase transformation is reduced gradually because the migration of the austenite stabilizing elements during the phase transformation is depressed. The $A_{\mathrm{s} 2}$ and $A_{\mathrm{f} 2}$ decrease with increasing the heating rate. When the $A_{\mathrm{s} 2}$ is lower than $A_{\mathrm{f} 1}$, the second step transformation overlaps the first step phase transformation. And finally the two steps phase transformation changes to one step phase transformation. That is the reason why the $A_{\mathrm{f}}$ decreases as the heating rate increases up to $10 \mathrm{~K} / \mathrm{s}$ in Fig. 1 . When the heating rate is $50 \mathrm{~K} / \mathrm{s}$, the martensite transforms to austenite within $130 \mathrm{~K}$ by one step. The first-order derivative of the dilatometric curve shows a steep valley rather than two extreme points in the phase transformation temperature range, which is definitely different from that of the sample with the heating rate of $0.05 \mathrm{~K} / \mathrm{s}$. This phenomenon demonstrates that the velocity of the phase transformation with high heating rate is high and the element diffusion is depressed, which are the typical features of the diffusionless phase transformation.

\subsection{Kinetics of the reverse transformation}

Given that the rapid heating rate of the HAZ is difficult to be measured accurately, the sample 


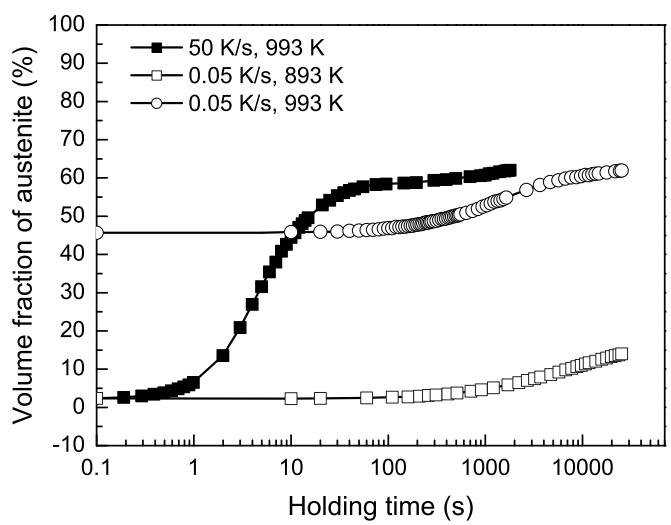

Fig. 3 Changes in volume fraction of austenite during the holding time in the intercritical tempering at different temperatures with various heating rates

which was heated with the heating rate of $50 \mathrm{~K} / \mathrm{s}$ was chosen to simulate the HAZ, based on the fact that the transformation mode does not change if the heating rate is higher than $10 \mathrm{~K} / \mathrm{s}$ (Fig. 1).

A series of samples were tempered at different temperatures with various heating rates to investigate the kinetics of the phase transformation by thermal dilatometric method. Fig. 3 shows the changes in austenite fraction at the isothermal holding temperature in samples 2, 4 and 7 during the intercritical tempering with different heating rates as a function of the holding time. It should be noted firstly, when the heating rate is $0.05 \mathrm{~K} / \mathrm{s}$, the $A_{\mathrm{s}}$ is $863 \mathrm{~K}$. However, when the heating rate is $50 \mathrm{~K} / \mathrm{s}$, it changes to $963 \mathrm{~K}$. Therefore, the samples 2 and 7 have the same relative austenizing temperature (i.e. $A_{\mathrm{s}}+30 \mathrm{~K}$ ), and samples 4 and 7 have the similar absolute austenizing temperature. In Fig. 3, when the heating rate is $0.05 \mathrm{~K} / \mathrm{s}$, the volume fractions of austenite in the samples austenized both at $893 \mathrm{~K}$ and $993 \mathrm{~K}$ increase gradually along with the holding time. It is similar to the diffusional transformation displayed in Fe- $13 \% \mathrm{Cr}-6 \% \mathrm{Ni}$ steel ${ }^{[8]}$. However, the volume fraction of austenite in the sample austenized at $993 \mathrm{~K}$ with heating rate of $50 \mathrm{~K} / \mathrm{s}$ increases rapidly within the first $20 \mathrm{~s}$ and then almost remains constant. According to the Ni diffusion coefficient in austenite measured by Hsieh and $\mathrm{Wu}^{[16]}$ and Fick's law of diffusion, the $\mathrm{Ni}$ diffusion within $20 \mathrm{~s}$ is negligible at $993 \mathrm{~K}$. Therefore, it is impossible to finish the martensite to austenite phase transformation within $20 \mathrm{~s}$ by diffusion in sample 7 .

\subsection{Microstructural analysis}

Fig. 4 shows the bright field TEM image and selected area diffraction pattern of the samples 3 and 7 after tempering at $993 \mathrm{~K}$ with different heating rates and holding time. In order to eliminate the effect of the slow heating on the microstructure evolution, the holding time of the samples 3 and 7 was set of

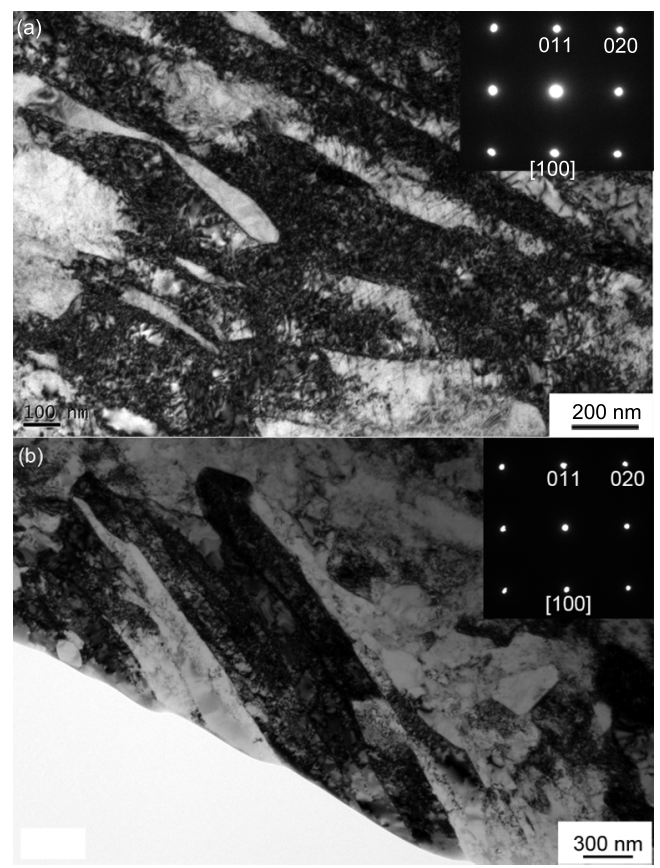

Fig. 4 The TEM image and SADP of the samples after $993 \mathrm{~K}$ tempered with different heating rates (a) $50 \mathrm{~K} / \mathrm{s}$ and (b) $0.05 \mathrm{~K} / \mathrm{s}$

$900 \mathrm{~s}$ and $1800 \mathrm{~s}$, respectively. The inset diffraction patterns indicate that there is no austenite in the two samples, which is in good agreement with the $\mathrm{XRD}$ results. If we divide the intercritical tempering into heating, isothermal holding and cooling process, such an observation means that the austenite in the heating and isothermal holding process totally transforms to martensite in the cooling process of tempering at $993 \mathrm{~K}$. Although both of the samples consist of martensite, some differences exist between them. Sample 7 remains the lathy structure and clear lath boundaries. This phenomenon may be interpreted as the martensite to austenite phase transformation being a diffusionless transformation in the intercritical tempering with high heating rate. Most of the reversed austenite grains have the same orientation as the prior austenite formed in normalizing $[7,13,17]$. When the cooling process in tempering begins, the austenite transforms to the same variants of the normalized martensite again. Thus the lath boundaries are retained perfectly in these two reverse transformations. Additionally, the twice diffusionless transformation brings many dislocations into the material (as shown in Fig. 4(a)), which induces the hardness of the sample rising to HV353. However, in sample 3 the diffusional nucleation and growth of the austenite in the heating and isothermal holding process of the intercritical tempering destroy the lath morphology and boundaries, as well as decrease the dislocation density in this sample, which reduces the hardness of this sample to $308 \mathrm{HV}$.

Additionally, in order to study the effect of the isothermal holding on the stability of austenite, an- 
other two rapidly heated samples were tempered at $993 \mathrm{~K}$ with the isothermal holding time of 0 and $900 \mathrm{~s}$ (i.e. samples 5 and 6 ). The amount of reversed austenite in them was also measured by XRD at room temperature with the same sample preparation. Unfortunately, both of them have no austenite at room temperature. This phenomenon indicates that the austenite occurred in the heating process with and without any elements redistribution during the holding process cannot remain to room temperature. This is because the concentrations of the austenite stabilizing elements in the austenite are as low as those in martensite when the phase transformation is finished in the heating process due to the diffusionless transformation. When the isothermal holding begins, some austenite stabilizing elements may diffusion from martensite to austenite. However, the $A_{\mathrm{s}}$ temperature of the sample with high heating rate is higher than that with the low heating rate. Therefore, the equilibrium austenite content is larger in the isothermal holding process of the intercritical tempering. This means that the relative enrichment of the austenite stabilizing elements from martensite to austenite during the isothermal holding will be diluted. Therefore the austenite does not have sufficient stability to retain room temperature ${ }^{[3,4]}$. Thus, the diffusionless transformation and higher $\mathrm{A}_{\mathrm{S}}$ temperature render it difficult for any austenite to remain at room temperature in the sample tempered at $993 \mathrm{~K}$ with the heating rate of $50 \mathrm{~K} / \mathrm{s}$.

When the heating rate is low, the sample tempered in the temperature range from $A_{\mathrm{s}}$ to $A_{\mathrm{s}}+100 \mathrm{~K}$ may have some reversed austenite at room temperature $^{[4,5,7]}$. The amount of austenite in a series of samples, which were tempered at 953, 973 and $1023 \mathrm{~K}$ with heating rate of $50 \mathrm{~K} / \mathrm{s}$ and holding time of $900 \mathrm{~s}$ (i.e. samples 8, 9 and 10), were also measured by XRD. It turns out that all the samples do not have any austenite, which demonstrates that the reversed austenite cannot be obtained in the sample tempered at the intercritical temperature range with high heating rate. That is why no reversed austenite exists in the intercritical tempered regions in the HAZ of the weld joint.

\subsection{Two-stage tempering}

As mentioned above, a proper fraction of reversed austenite can improve the ductility and toughness of the material. In order to obtain some reversed austenite in the intercritical tempered sample with high heating rate, sample 6 was tempered at $893 \mathrm{~K}$ again with heating rate of $0.05 \mathrm{~K} / \mathrm{s}$ (i.e. sample 11 ). Some stable austenite was detected at room temperature after two-stage tempering, although the austenite amount is a little less than that in sample 1 shown in Fig. 5. This phenomenon is different from the twostage tempering heat treatment both with low heating rate, which is deliberately designed to increase

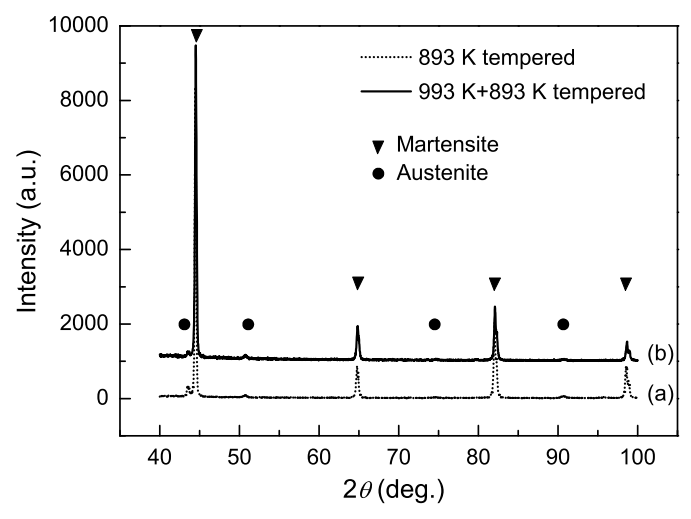

Fig. 5 The XRD spectra of samples 1 (a) and 11 (b)

the austenite volume fraction in the castings. After the intercritical tempering with low heating rate, the sample is composed of tempered martensite, revered austenite and a small amount of untempered martensite. The lamellar structure provides more interfaces for the reversed austenite nucleation and elements concentration fluctuation for the elements diffusion during the second stage tempering ${ }^{[18]}$. However, the sample consists of tempered martensite and untempered martensite after intercritical tempering with high heating rate, which has the similar lath boundaries to the normalized sample. During the second stage tempering, there is no additional nucleation sites for the austenite. Therefore, adding a second stage tempering to sample 6 can only induce a little austenite to it.

Thus, adding an intercritical tempering with low heating rate in the rapid heated tempered sample can induce some reversed austenite in it and improve its ductility and toughness. However, the tempering parameters should be different to that used for the castings in order to obtain the same reversed austenite fraction and mechanical properties.

\section{Conclusions}

(1) The mechanism of the martensite to austenite transformation in $\mathrm{Fe}-13 \% \mathrm{Cr}-4 \% \mathrm{Ni}-\mathrm{Mo}$ during the intercritical tempering changes from diffusion to diffusionless when the heating rate is higher than $10 \mathrm{~K} / \mathrm{s}$.

(2) It is difficult for any austenite to remain at room temperature during the intercritical tempering between $A_{\mathrm{s}}$ and $A_{\mathrm{f}}$ with high heating rate because of the diffusionless transformation and higher $A_{\mathrm{s}}$ temperature.

(3) Adding a proper intercritical tempering with low heating rate can induce some reversed austenite in the rapidly heated sample. However, the tempering parameters should be different to that used for the castings in order to obtain the similar reversed austenite fraction and mechanical properties. 


\section{Acknowledgements}

The authors are grateful to Dr. Xiahan Sang at University of Pittsburgh for the useful discussions. The authors also gratefully acknowledge the financial support from the National Science Foundation of China (No. 51201167) and the Youth Innovation Promotion Association Chinese Academy of Sciences and National Science and Technology Major Project ( No. 2011ZX06004-016).

\section{REFERENCES}

[1] P.D. Bilmes, C. Llorente and J.P. Ipina, J. Mater. Eng. Perform. 9 (2000) 609.

[2] Y. Iwabuchi, JSME Int. 46 (2003) 441.

[3] B.A. Tabatabae, F. Ashrafizadeh and A.M. Hassanli, ISIJ Int. 51 (2011) 471.

[4] Y.Y. Song, X.Y. Li, L.J. Rong and Y.Y. Li, Mater. Sci. Eng. A 528 (2011) 4075.

[5] P. Wang, S.P. Lu, D.Z. Li, X.H. Kang and Y.Y. Li, Acta Metall. Sin. 44 (2008) 681.(in Chinese)

[6] Y. Iwabuchi, I. Kobayashi, M. Ohmori and M. Kikuchi, J. Jpn. Inst. Met. 58 (1994) 411

[7] N. Nakada, T. Tsuchiyama, S. Takaki and S.
Hashizume, ISIJ Int. 47 (2007) 1527.

[8] N. Nakada, T. Tsuchiyama, S. Takaki and N. Miyano, ISIJ Int. 51 (2011) 299

[9] D. Carrouge, Ph.D. Dessertation, University of Cambridge, 2002

[10] H. Smith and D.R.F. West, J. Mater. Sci. 8 (1973) 1413.

[11] D.S. Leem, Y.D. Lee, J.H. Jun and C.S. Choi, Scr. Mater. 45 (2001) 767.

[12] Y.K. Lee, H.C. Shin, D.S. Leem, J.Y. Choi, W. Jin and C.S. Choi, Mater. Sci. Technol. 13 (2003) 393.

[13] S.J. Lee, Y.M. Park and Y.K. Lee, Mater. Sci. Eng. A 515 (2009) 32.

[14] Y. Lv, B. Hutchinson, D. A. Molodov and G. Gottstein, Acta Mater. 58 (2010) 3079.

[15] R. Kapoor, L. Kumar and I.S. Batra, Mater. Sci. Eng. A 352 (2003) 318.

[16] C.C. Hsieh and W. Wu, J. Alloys Compd. 506 (2010) 820.

[17] K. Tomimura, S. Takaki and Y. Tokunaga, ISIJ Int. 31 (1991) 1431.

[18] P.D. Bilmes, M. Solari and C.L. Llorente, Mater. Charact. 46 (2001) 285. 